Changing English 2015

Vol 22, No.3, 326-334

\title{
Reading the Multi-modal Ologies: New Literacy Challenges or Old Wine in new Bottles?
}

Sandra Williams

School of Education, University of Brighton, UK

Emailsjw7@brighton.ac.uk

In this article the Ologies series of books are interrogated with a focus on whether they present new challenges for the reader or merely require previously acquired skills. The multimodal texts are unusual in that they combine non-fiction with fantasy while including tactile elements such as flaps, pull outs and items to stroke. Ways of approaching multimodal texts are discussed with reference to the work of Kress, van Leeuwen and Moss. Finally reference is made to Mackey's research on multimodal platforms applying her terms 'playing the text', the notion of 'performance' and 'engaging in the rules of the game'. The conclusion leaves the question posed in the title open and suggests further research into actual readers will reveal more.

Key Words: Ologies; multimodal; fiction/non-fiction; tactile; irony; pastiche; playing the text

According Alan Kay, 'World changing inventions are so different that they initially have to masquerade as "better old things" rather than "completely new things" '(Mackey 2002,98).

Conversely, Mackey implies an underlying sameness: 'Many new media involve old wine in new bottles'(101).

In this article I will discuss whether the Ologies series offers completely new challenges for the reader or merely requires the application of previously acquired skills. The Ologies series of books will be introduced offering an initial analysis of these seemingly innovative texts with their interplay of fiction and non-fiction. Reference will be made to the work of Kress and van Leeuwen followed by a consideration of Margaret Mackey's term 'playing the text'. Finally a conclusion explores whether the texts offer new challenges for the reader. 


\section{The Ologies Series}

The term ology implies the study of a subject and the most conventional title is Mythology (Steer 2007), but also included in the series is Dragonology (Steer 2003), Egyptology (Steer 2004), Wizardology (Steer 2005), Piratology (Steer 2006), Monsterology (Steer 2008a), Spyology (Steer 2008), Alienology (Steer 2010). They large (A3 size), with brightly coloured covers which resemble medieval books all having 'precious' stones surrounding an illustration in the centre. On opening any of the books there is a sense of a non-fiction text in which spatial organisation is paramount rather than linear reading. Written text combines with illustrations, diagrams, headings, subheadings, charts and maps.

A significant element is the tactile. Many of the pages resemble $19^{\text {th }}$ century moveable books as more information can be revealed by lifting a flap or opening out a page. As such these devices may be seen as the forerunners of hypertext in electronic media. In addition, a dragon's skin can be stroked, the dust from a burnt Phoenix felt, nautical knots tied, a golden quill removed and a cabinet of wonders opened, items therein touched and added to by the reader with their own curiosity.

The provenance of the texts is also of interest. On close examination all the books are framed as purportedly facsimiles of ancient books that have been 'found'. For example Piratology (from the $17^{\text {th }}$ century) was discovered in an old sea chest, Wizardology (from Elizabethan times) was forged from an oak tree where Merlin is imprisoned, Egyptology (a journal written in the 1920s) unearthed after 80 years and sent to a relative, Dragonolgy (a manual published in 1896) was found in a bookshop in 7 Dials, London.

Spyology is particularly intriguing: 
The attached study on the science of spying, known among agents as Spyology, or sometimes Tradecraft, was prepared by a member of my staff known as Agent K. I had asked Agent K - who also goes by the alias Spencer Blake - to write this manual during the course of his last mission, the deadly Operation CODEX. And, while I am pleased to report that he did indeed succeed in saving the civilised world yet again, it seems that he perished in the process. It was therefore a great surprise to me when this book arrived at the headquarters of MI6 in an unmarked envelop several months after his disappearance. As well as being a complete guide to Spyology, it sets the reader a series of intriguing challenges to solve based on the Operation CODEX material. (Note: Ology pages are not numbered)

The book contains a pull-out encryption device which can be used to de-code a number of pieces of information hidden in the text.

In all the books in the Ologies series the reader is constructed and invited to take on a role.

Here are some examples:

Wizardology: an apprentice wizard:

Were you to have been the usual sort of apprentice, you would have spent nearly all of your time here: being punished for your foolishness, chastised for your laziness, laundering robes, stirring cauldrons, preparing potions, researching spells, taking care of familiars and polishing wands.

Dragonology: a young natural historian:

As dragonologists, we must be prepared to refute those who claim that dragons are unreal. Consider how many creatures there may be that are still unknown to accepted science.

This is a sample record book of the type used by field dragonologists. Note that you will need to make your own, with a fire-proof and probably waterproof cover. I have included some sample records.

Spyology: A spy.

As a new recruit to the secret service, your first task is to realise the far reaching expectations of living the life of a spy. From now on, yours will be a life cloaked in secrecy, spent in the service of your country. You will be unable to inform 
even your closest friends or relations of your real occupation.

From this brief introduction it can be seen that the texts are multifaceted which leads to consideration of how the texts might be approached.

\section{Fiction or Non-Fiction?}

Initially the layout of the page invites reading behaviour associated with non-fiction.

On opening a page the eye roves first before focusing on one particular area. Meek $(1996$ ',9)

refers to this as 'radial' movement. Such pages invite a different kind of reading:

We read them differently from the way we read continuous print, making different choices about where to start reading: often the eye falls on a strong central image, or a coloured text box presented as a 'fascinating fact'; or the arrows on a diagram might direct our gaze. (QCA/UKLA 2004, 5)

Kress and van Leeuwen observe how these texts invite skimming and scanning:

The more a text makes use of subheadings, emphatic devices (italics, bold type, underlining), numbered lines of typical elements or characteristics of some phenomenon, tables, diagram and so on, the more likely it is to scanned, skip-read, 'used' rather than read: linear reading is gradually losing ground (Kress and van Leeuwen, 2006, 205).

Similarly, when reading the Ologies time is spent scanning before concentrating on one particular spot. Moss $(2001,108)$ highlights the different relationship between text and image in double page spreads noting: 'The (linear) logics of time versus the (non-linear) logics of space construct different kinds of pathways through the text'.

This can be illustrated with a detailed description from the first double page spread in Monsterology which invites both linear reading, skimming and scanning plus close attention to visual features: (note: the illustration is reproduced in the published version). 
Top left centre in block capitals set in green decorated scroll with hints of Art Nouveau is the heading 'CHAPTER 1'. Centred underneath also in capitals is the word 'FOREWORD' and centred under that in smaller print: 'THE SEARCH FOR FABULOUS BEASTS'. The first block of print is linear: a first person narrative from the perspective of the 'author' Dr. Ernest Drake, which is also centred:

' In 1898, I set sail in my yacht, Hydra, on a year-long voyage of discovery....'

Central and across both pages is non-linear: a large detailed depiction of a griffin in the medium of water colour. It is labelled with common and Latin names: GRIFFIN Gryps vulgaris. To the left is a young Edwardian woman sketching the creature with information concerning the creature in italics 'Like many so-called monsters, the griffin is a timid beast...' To the right at the end of the long tail there is a sketch of an Edwardian girl with the advice: You may sit safely near a griffin's tail - as long as you are not tempted to pull it! Sitting on the Griffin itself is a young Edwardian lad. It is this illustration that is the immediate focus when opening the page.

Bottom left is a table of contents set in a frame. To the right of this below the Griffin's head is a section in two justified columns headed in block capitals 'CHALLENGING THE CHARLATANS: '. In the voice of Drake it recounts the frauds committed by showman Albert Kock in New York 1845. Below the text crossing both columns and boxed in a black and white is an engraving of Kock's so called sea serpent.

The right hand page continues with more information. The first section taking up the space above the Griffin concerns mistaken identities under the heading 'ANCIENT AUTHORS' which 
has 5 lines of justified print. To the right of this are 4 oblong boxes depicting in black and white sketches of mythical and actual creatures. One compares the unicorn ('supposedly mythical') with a rhinoceros ('actual') in the other the Mongolian death worm ('mythical') with a Lindworm ('actual'). Below the box in two justified columns is more information about the pictures.

Bottom right underneath the Griffin, in a frame headed 'UNEARTHING EVIDENCE' Drake's narrative continues:

'On my voyage around the world I sought out evidence for the existence of many fabulous beats and found it in plentiful supply.....'

The text is justified with an illustration of a Minotaur to the right. Finally to the left of this box a small section headed MODERN EQUIPMENT with a black and white illustration of a large squid and a diver.

The question is how do you read this busy page? Kress and van Leeuwen note that trajectories can move in a circle:

Our assumption is that the most plausible reading path is the one in which readers begin by glancing at the photos, and then make a new start from left to right, from headline to photo, after which, optionally, they move to the body of the verbal text. Such pages can be 'scanned' or read, just as pictures can be taken in at a glance or scrutinized for their every detail (Kress and van Leeuwen 2006, 205).

They also observe that there are different levels of guidance:

Texts encode reading paths to different degrees. Some, though no longer densely printed pages, still take the readers by the hand, guiding them firmly through the text. Others (we might call them 'semi-linear' texts) at best provide readers with a few hints and suggestions, and for the rest leave the readers to their own devices. In again 
others we can, with the best will in the world, not detect any reading path that is more plausible than any number of others (Kress and van Leeuwen, 2006, 206).

I suggest there are guides for the reader in the layout of this page. As noted above, the initial focus is on the Griffin in the centre but there is a left right orientation as the wings and the tale stretch from verso to rechto. However, after that it appears the reader is not pushed to read in a specific sequence. The 'information' sections in boxes can be read in any order. Hence this might be categorised as a 'semi-linear' text.

The key question is if/when the linear elements are read. When I first 'read' an Ology text, I did not pick up the thread but spent more time gazing, lifting, moving around the page. It was only half way through that I began to see that there was an important narrative thread to pick up. This means the Ologies have to be read closely at some stage rather than only scanned. Significantly games are being played with the reader because, while presented as fact, the information offered is fiction. And this creates a tension between the two; for with fantasy the reader has to suspend disbelief while they need to be critical when reading nonfiction. For example, in the page from Monsterology described above, Ernest Drake's journal invites the reader to enter into the narrative concerning the monsters he has discovered. In addition, there is information from Drake concerning charlatans to warn the reader not to believe everything they hear or see. Additional information concerning real and imagined mythical creatures, while presented as fact, is with one exception untrue. The outcome of this is a tension the reader has between believing Drake's account while also maintaining scepticism about what he says he has found.

As such, is it difficult to classify the Ologies for in many ways they resemble a children's information book with predominant text-types from non-fiction. However, while 
information offered is presented as factual we are clearly in the realm of fantasy. For dragons, aliens, vampires, wizards, myths and legends are considered to be part of a secondary world . Significantly, there are other elements which sit with fiction rather than non-fiction: irony, intertextuality and pastiche.

A second link with fiction is that all have a recognisable character as narrator. Captain Lubber's ship's log in Piratology, John Oro's annotations in Mythology, Merlin's instruction manual for an apprentice wizard in Wizardology, Dr Ernest Drake's natural history books on Dragons and Monsters. So in this case the text is closer to fiction in which a close relationship is established between reader and text as opposed to the more distanced nature usually associated with an information text.

All the books in the series have strong intertexual links which implies the reader brings to the text some previous knowledge of the genre of non-fiction; the novel and of other reading in variety of media.

The linear narrative in each title is significant. I will take one example from Mythology. The conceit is that the book is a facsimile of Lady Hestor's journal which she kept when exploring ancient Greek remains and concerns information about Greek myths and legends. A certain John Oro is using this book as a guide and has annotated it in the margin. So in this case we have two narratives. As John Oro (and there is a big clue in his name) continues his travels he becomes more avaricious. More clues about what might happen to him are dropped with reference to King Midas which is followed by an open out mini-book relating the myth of Midas . At this point the reader is placed in an ironical position in which they know 
more than John Oro. Finally, Oro makes a deal with Zeus and gradually the pages of the book begin to turn gold until on the final page all that remains is his golden quill. And this is a physical object that the reader can remove and hold. During the course of reading this book much information is offered concerning Greek Mythology and $19^{\text {th }}$ century discoveries such as those of Myceane by Schliemann.

So it can be seen that on one level an Ologies series book looks like a well-designed nonfiction book such as those produced by Dorling Kindersley which require such reading skills as skimming and scanning for specific information. But on another hand they have features which indicate they are clearly fiction which involves close engagement with plot, character and setting with attendant willingness to enter a secondary world.

In terms of binary oppositions, Table 1 offers some differences between the two.

\section{Table 1. Characteristics of fiction and non-fiction books}

\section{Fiction}

Chapters

Predominantly print, linear

Genre: historical, fantasy etc

First person, third person, dialogue

Read left to right continuously

Has a metaphorical truth which does

not necessarily age

Operates on more than one level

One author (plus illustrator)

The writing is paramount

Immediacy: Immersion into the text

\section{Non-Fiction}

Chapters plus contents page, index, glossary

Print, subheadings, pictures, diagrams

Text-types: instruction, description, procedure

Third person, use of the passive

Skimmed, scanned, gazed at

Information should be up-to-date, factual

One level only

Often a team production

Presentation paramount

Hypermediacy: reminds viewer of the medium

It is clear that taking such a perspective lacks nuance. Graphic novels and picture books are not taken into account while journals, biography and autobiography have features of both fiction and non-fiction. Therefore, I would argue that the focus should move to the crucial differences between how the reader approaches fiction and non-fiction. The former requires 
immersion and the willing suspension of disbelief while the latter assumes a more distanced and critical stance. While the Ologies certainly have the features of non-fiction, and do offer information for the reader, they also operative on a number of levels, are playful, ironic, intertextual and imply a reader who is able to oscillate between genres. A significant tension is created between reading fiction and non-fiction. What the Ologies present are what I term 'fantasy facts' and this is something new.

\section{Kinds of Reading}

With this in mind, the key question arises concerning what is required of the reader. Is it something new?

Pahl and Roswell note:

What is it that makes reading and writing different today than it was a decade or two ago? The answer lies in multimodality; in a concept of communication that subsumes the written, the visual, the gestural and the tactile into one entity (Pahl and Rowsell 2005, 26).

Now it could be argued that picture books and comics, by no means new, are multi-modal. Reading comics requires a multi-modal approach in which picture, speech bubble, and narrative combine. Similarly Victorian flap and pop-up books offer a tactile engagement with 3-dimensional views. Nevertheless it could be argued that the Ologies with the combination of fiction and non-fiction do appear to be something new.

Certainly implied is a reader who is able to bring both their knowledge of other texts plus their world knowledge when engaged with the book. Moreover, they need to be able to pick up irony, pastiche and intertextuality. Irony runs throughout the texts in both the disguised 
'factual' presentation and in the fictive elements. The 'facts' in terms of aliens, dragons, vampires are clearly ironic and the fun is the mismatch between the non-fiction form of presentation with the fiction which is presented. In addition, the reader is often placed in a position where they know more about what is taking place than the explorers, wizards, spymasters. Intertextuality is also a significant element both in terms of picking up how nonfiction is presented and with reference to historical accounts of explorers, sci-fi, horror fiction, instruction manuals. Moreover, the reader is invited to question the authenticity of the text while also engaging in the 'willing suspension of disbelief'. The former is a skill when engaging with non-fiction while the latter is part of reading fiction. As such, this requires a high level of sophistication from the reader.

Crucially the texts are playful and this brings us to the research conducted by Margaret Mackey (2002) into teenagers engaging in a variety of different media: print, electronic book, Video, DVD, computer game, and CD-ROM over a period of 18 months. An important element was boundary crossing in which students moved in and out of the world of the story itself without leaving the game or show in which the story was located (15) and clearly this is seen in the Ologies series which invites an engagement with the narrative and the character in a secondary world while also involving a cooler reading of 'information' material or a pause to try out a game or a puzzle. The ability to oscillate is significant. Mackey found that play was important:

In the final analysis of this study, the ideas encompassed in that very fluid and multifaceted word play became extremely useful in exploring some common questions of text interpretation in a variety of media (Mackey 2002,16).

And it is this word 'play' that is highlighted in Mackey's conclusions. She discusses how the verb 'to read' is inadequate to use with a range of technologies that involve narrative and 
comes up with the idea of 'playing the text' rather than 'reading the text' which is a useful term as this can be applied to the Ologies series. She discusses the notion of 'as if' stepping into the fictional universe. This is what Ologies are inviting for they actively create a role for the reader which involves the willing suspension of disbelief. Clearly there are links here to drama and what is required when watching a play.

And this links to another of Mackey's observations: 'The issue of performance is one that is generally undervalued when it comes to many forms of text processing, particularly to reading' (Mackey 2002, 183).

This applies to an Ologies reader who is required to suspend disbelief and perform a role. She goes on to say: 'Performing involves some kind of bodily immersion in the activity' (Mackey 2002, 183).

This is clearly the case with Ologies because of the tactile nature of the books. The text is constantly being handled, opened, smoothed, lifted. Objects can be removed and used. With a combination of gaze and close attention to the word, the reader flicks backwards and forwards to see the clues, catches the irony, makes the links.

Mackey also makes a connection with gaming for the Ologies reader must accept the rules and conventions of the game they are invited to play. They need to take on the role that is invited and, significantly, understand that a game is indeed being played.

So, it could be argued that there is a combination of the familiar old wine from the $19^{\text {th }}$ century children's book published with a post-modern bottle of the knowing, intertextual 
game being played. So, I don't have a definitive answer about whether we have old wine in new bottles or something completely new but certainly Mackey and others are providing the necessary new vocabulary and new ways at looking at the relationships between traditional book and the multimodal. And this, of course, invites speculation concerning mediating the Ologies with pupils. What kinds of skills and attitudes are required in order to gain the most from such playful publications? I would say that the skills required for reading fiction and non-fiction are not new but here they are combined in the same text as opposed to separate publications. So what is required is the ability to shift quickly between genres and apply different skills as appropriate. Skimming and scanning is fine initially but the reader will not get the irony unless they pay close attention to print and carefully scrutinise the images. It could be argued that the Ologies series are multi-layered texts that 'teach what readers learn', Meek (1987) thus offering a rich source of textual experience.

The next stage will be to conduct research with actual readers to see how they engage with the Ologies series.

\section{References:}

Kress, G. and T. van Leeuwen, T. 2006. ( $2^{\text {nd }}$ edition) Reading Images. The Grammar of Visual Design. London: Routledge

Mackay, M. 2001. Literacies Across Media. Playing the Text. London: Routledge

Meek, M. 1987. How Texts Teach What Readers Learn. Stroud: Thimble Press

Meek, M. 1996. Information \& Book Learning. Stroud: Thimble Press

Moss, G. 2001. “To Work or Play?” Literacy 35 (3): 106-110, Oxford: Blackwell/UKRA

Pahl, K and J. Rowsell. 2005. Literacy and Education: Understanding the New Literacy

Studies in the Classroom. London: Paul Chapman Publishing

QCA/UKLA More than Words: Multimodal Texts in the Classroom. London: QCA/UKLA. Accessed January 26, 2015.

http://www.open.edu/openlearnworks/pluginfile.php/5780/mod_resource/content/1/18472128 75.pdf

Steer, D. 2003. Dragonlogy: The Complete Books of Dragons. Dorking: Templar

Steer, D. 2004. Egyptology: Search for the Tomb of Osiris. Dorking: Templar

Steer, D. 2005. Wizardology: The Books of the Secrets of Merlin. Dorking: Templar

Steer, D. 2006. Piratology: A Pirate Hunter's Companion. Dorking: Templar

Steer, D. 2007. Mythology: Greek Gods, Heroes, \& Monsters. Dorking: Templar 
Steer, D. 2008a. Monsterology: The Complete Book of Fabulous Beasts. Dorking: Templar Steer, D. 2008b. Spyology: The Complete Book of Spycraft. Dorking: Templar

Steer, D. 2010. Alienology: The Complete Book of Extraterrestrials. Dorking: Templar

\section{Notes on contributor}

Sandra Williams is a Senior Lecturer in the School of Education at the University of Brighton, specialising in Children's Literature. Her PhD thesis (1997) drew out cultural indicators of Englishness embedded in children's literature texts. Previous publications and conference papers have focused on two areas: linking implied reader theory to literacy and emergent children's literature. Recently she has become interested in the Ologies series and gave a paper at the biennial International Research Society for Children's Literature conference, 'Children's Literature and Media Cultures', in Maastrict in 2013. She is currently conducting empirical research with young Ology readers.

\section{Disclosure statement}

No potential conflict of interest was reported by the author. 